\title{
An Implementation of the IT Fundamentals Knowledge Area in an Introductory IT Course
}

\author{
Cheryl Aasheim, Choong Kwon Lee, and Han Reichgelt \\ Georgia Southern University, Statesboro, GA, USA
}

\section{caasheim@georgiasouthern.edu cklee@georgiasouthern.edu, han@georgiasouthern.edu \\ Executive Summary}

The recently promulgated IT model curriculum contains IT fundamentals (ITF) as one of its knowledge areas. It is intended to give students a broad understanding of (1) the IT profession and the skills that students must develop to become successful IT professionals and (2) the academic discipline of IT and its relationship to other disciplines. The model curriculum recommends 33 lecture hours to complete the IT fundamentals knowledge.

The model curriculum also recommends that the material relevant to the IT fundamentals knowledge area be offered early in the curriculum, for example in an Introduction to IT course; however, many institutions will have to include additional material in an introductory IT course. For example, the Introduction to IT course at Georgia Southern University is used to introduce students to the available second disciplines (an important part of the Georgia Southern IT curriculum aimed at providing students with in-depth knowledge of an IT application domain), some productivity tools, and SQL in addition to an introduction to the discipline of IT.

For many programs there may be too much material in an introductory IT course. This paper describes how Georgia Southern University resolved this problem by describing the structure of the introductory course at Georgia Southern, its assessment methods, and the relationship between the course and the ITF knowledge area and how those aspects of the ITF knowledge area that are not covered in the introductory course are covered elsewhere in the program.

Keywords: Model Curricula in Computing, IT Model Curriculum, IT Fundamentals Knowledge Area, Assessment

\section{Introduction}

Model curricula have played an important role in helping institutions design and deliver programs

Material published as part of this journal, either on-line or in print, is copyrighted by the publisher of the Journal of Information Technology Education. Permission to make digital or paper copy of part or all of these works for personal or classroom use is granted without fee provided that the copies are not made or distributed for profit or commercial advantage AND that copies 1) bear this notice in full and 2) give the full citation on the first page. It is permissible to abstract these works so long as credit is given. To copy in all other cases or to republish or to post on a server or to redistribute to lists requires specific permission and payment of a fee. Contact Editor@JITE.org to request redistribution permission. in a wide variety of disciplines. As model curricula are typically formulated by groups of representatives from programs that are highly regarded in a particular field, they give institutions guidance on what to include in particular degree programs. Moreover, authors of textbooks often turn to model curricula for suggestions on what material to include. On the other hand, one sometimes hears com- 
plaints that model curricula stifle curricular innovation, as it is not unusual for institutions to base their programs solely on a model curriculum without a critical reflection on the match between the model curriculum and the specific needs of their students, graduates, and potential employers.

One of the oldest efforts to formulate a model curriculum has been in the field of computer science (CS). The first CS model curriculum was published by Association for Computing Machinery (ACM) in 1968, and it has been regularly updated with the latest version being published in 2001. Recently, the ACM, in collaboration with the Computer Society of the Institute of Electrical and Electronics Engineers (IEEE) and the Association for Information Systems (AIS), has embarked on a more ambitious project that is intended to result in model curricula in five computing disciplines (computer engineering, computer science, information systems, information technology and software engineering), as well as an overview volume that summarizes the content of the model curricula documents for the different computing disciplines and lays out the differences and similarities between the various computing fields (www.acm.org/education/). One reason for the production of the overview volume is to provide a basis for understanding the major computing disciplines and how the respective undergraduate degree programs compare and complement one another. While the overview report is aimed primarily at academics, the need for providing a clear distinction between the computing disciplines extends beyond that community. Many parents and prospective students often seem confused about the plethora of computing degrees offered by various institutions and need guidance to select the degree program that is most appropriate, given the interests and talents of the prospective student.

The first draft of the overview volume was published in 2005 and summarizes the content of the model curricula in computer engineering (published in 2004), computer science (published in 2001), information systems (published in 2002), information technology (published in 2005), and software engineering (published in 2004). The differences between the different model curricula in the way in which they formulate curricular recommendations are significant. For example, the information systems model curriculum is organized around courses. The software engineering model curriculum defines a body of knowledge for software engineering and then gives a set of sample courses to teach the body of knowledge. The computer engineering, computer science and information technology model curricula consist of a set of knowledge areas, each consisting of a set of knowledge units, which themselves are defined in terms of topics and student learning outcomes. Computer engineering and computer science distinguish between core knowledge units, which every student in the discipline is expected to master, and elective knowledge units, which only some students are expected to complete. The information technology volume does not distinguish between core and elective knowledge units but associates core and elective learning outcomes with most knowledge units. Core learning outcomes are expected to be achieved by all students graduating from an information technology program, whereas elective learning outcomes are expected to be met only by those students who specialize in the knowledge area with which the knowledge unit is associated. The reasons for this slightly different organization are explained in Lawson et al. (2005).

The IT Model Curriculum, available at http://sigite.acm.org/activities/curriculum/, consists of 12 knowledge areas, namely

1. information technology fundamentals;

2. human computer interaction;

3. information assurance and security;

4. information management;

5. integrative programming and technologies; 
6. networking;

7. platform technologies;

8. programming fundamentals;

9. system administration and maintenance;

10. system integration and architecture;

11. social and professional issues;

12. web systems and technologies.

Of particular interest in this paper is the IT fundamentals (ITF) knowledge area. ITF is intended to provide students with a set of foundation skills and provide an overview of the discipline of IT and its relationship to other computing disciplines. It is also intended to help students understand the diverse contexts in which IT is used and the challenges inherent in the diffusion of innovative technology. Given its foundational nature, it will not come as a surprise that the model curriculum recommends that ITF is covered early in a student's program of study, and it seems most logical that this knowledge area be covered in an introductory course in a baccalaureate program in IT.

Following the model curricula in computer engineering, computer science and software engineering, the IT model curriculum recommends minimum coverage for each knowledge area, measured in lecture hours, although, again following the other model curricula, the document explicitly states that this should not be regarded as an endorsement of the lecture as the only, or even the most appropriate way, to deliver material to students. The recommended minimum coverage of ITF is 33 lecture hours; however, a typical three-credit semester course gives an instructor, at most, 45 lecture hours, and many programs will have to include additional material in an introductory course.

For example, an important element of the IT program at Georgia Southern University is the inclusion of second disciplines, coherent sets of seven courses in an IT application area, such as electronic broadcasting, law enforcement, music technology, and supply chain management (Reichgelt, Price, \& Zhang, 2002a, 2002b). Since students must begin introductory courses in their second discipline relatively early in their academic program, it is important that they be exposed to the range of second disciplines available to them early, and the most appropriate place to do this is in the introductory IT course. Also, students enrolling in the introductory IT course at Georgia Southern are not expected to have taken a computer literacy course beforehand, and it has become clear that many are weak in the use of spreadsheets. Since the department strongly believes that IT graduates must be conversant with basic productivity tools, including spreadsheets, the program must cover the basics of spreadsheet applications, and the introductory course is the most appropriate place in the curriculum to do so. Finally, the introductory IT course must also provide a basic coverage of SQL because the web design course, which covers n-tier architectures and requires a basic knowledge of SQL, is taught before the database course in which SQL is normally presented.

While the additional material that has to be covered in an introductory IT course is likely to differ between institutions, it is likely that many, if not all, IT programs will have to cover some additional material. Given that the amount of lecture hours required by ITF takes up about $70 \%$ of a typical course, considerable pressure is placed upon instructors in introductory IT courses to cover both the ITF material and whatever additional material needs to be included.

The intent of this paper, which is an expansion of an earlier paper (Aasheim, Lee, \& Reichgelt, 2005), is to describe how Georgia Southern University has implemented the ITF knowledge area prescribed in the IT model curriculum in its introductory IT course, coded IT 1130. The next two 
sections provide more details about the IT fundamentals knowledge area and the Introduction to IT course offered at Georgia Southern University. These are followed by a section on the assessment strategy used in the Introduction to IT course and some concluding remarks.

\section{The IT Fundamentals Knowledge Area}

The IT Model Curriculum follows the example set by the Computer Science model curriculum (http://www.acm.org/education/curricula.html) and distinguishes between a number of knowledge areas, each consisting of a number of knowledge units. Knowledge units are themselves composed of topics and learning outcomes. Given the foundational nature of ITF, it should come as no surprise that ITF only has core learning outcomes associated with it.

The list below gives the knowledge units in the ITF knowledge area and the learning outcomes associated with each. The number behind each knowledge unit is the minimum recommended coverage expressed in lecture hours.

ITF1. Pervasive themes in IT (17)

Learning Outcomes:

1. Describe the components of IT systems and their interrelationships.

2. Describe how complexity occurs in IT.

3. Recognize that an IT professional must know how to manage complexity.

4. List examples of tools and methods used in IT for managing complexity.

5. Describe the role of the IT professional as the user advocate.

6. Explain why life-long learning and continued professional development is critical for an IT professional.

7. Explain why adaptability and interpersonal skills are important to an IT professional.

8. Distinguish between data and information, and describe the interrelationship.

9. Describe the importance of data and information in IT.

10. Explain why the mastery of information and communication technologies is important to an IT professional.

11. Explain why the IAS perspective needs to pervade all aspects of IT.

ITF2. Organizational Issues (6)

Learning Outcomes:

1. Describe the elements of a feasible IT application.

2. Identify the extent and activities involved in an IT application.

3. Understand the requirements of the business processes.

4. Outline the project management processes.

5. List the integration processes.

ITF3. History of IT (3)

Learning Outcomes:

1. Outline the history of computing technology. 
2. Describe significant impacts of computing on society.

3. Describe significant changes in human-computer interaction.

4. Outline the history of the Internet.

ITF4. IT and its related and informing disciplines (3)

\section{Learning Outcomes:}

1. Define "information technology."

2. Describe the relationship between IT and other computing disciplines.

3. Describe the relationship between IT and non-computing disciplines.

4. Explain why mathematics and statistics are important in IT.

\section{ITF5. Application domains (2)}

\section{Learning Outcomes:}

1. Describe the application of IT in non-computing disciplines.

2. Describe how IT has impacted almost all aspects of modern living.

3. Describe ways and extents in which IT has changed the interaction and communication in our society.

4. Describe how IT has impacted the globalization of world economy, culture, political systems, health, security, warfare, etc.

ITF6. Application of math and statistics to IT (2)

\section{Learning Outcomes:}

1. Recognize the foundation of IT is built upon the various aspects of mathematics.

2. Understand the number systems used in computation.

3. Explain data representation and encoding systems.

4. Describe the current encryption methods and their limitations.

5. Describe the pervasive usage of mathematical concepts, such as functions, relations, sets as well as basic logic used in programming.

6. Recognize the value of probability and statistics.

7. Describe the basic data analysis concepts and methods used in IT applications.

While most of the knowledge units are relatively self-explanatory, the first knowledge unit perhaps requires some additional explanation. The IT model curriculum argues that there are a number of themes that ought to pervade any IT program. Specifically, these are

- user centeredness and advocacy

- information assurance and security

- the ability to manage complexity through abstraction and modeling, best practices, patterns, standards, and the use of appropriate tools

- a deep understanding of information and communication technologies and their associated tools 
- adaptability

- professionalism (life-long learning, professional development, ethics, responsibility)

- interpersonal skills

Since the themes in a sense define much of the academic field of IT, the model curriculum also argues that students should be exposed to these themes early in their curriculum. The argument is that an early explicit exposure to these themes will better enable students to see the linkages between the various courses that make up an IT program.

\section{The Introduction to IT Course at Georgia Southern}

The IT program at Georgia Southern University was designed with a set of explicitly formulated program outcomes in mind, describing the skills and knowledge graduates can be expected to have as they graduated from the program. Specifically, on graduation students are expected to be able to

1. Demonstrate expertise in the core information technologies;

2. Demonstrate sufficient understanding of an application domain to be able to develop IT applications suitable for that application domain;

3. Identify and define the requirements that must be satisfied to address the problems or opportunities faced by an organization or individual;

4. Design effective and usable IT-based solutions and integrate them into the user environment;

5. Demonstrate an understanding of best practices and standards and their application to the user environment;

6. Identify and evaluate current and emerging technologies and assess their applicability to address individual and organizational needs;

7. Create and implement effective project plans for IT-based systems;

8. Work effectively in project teams to develop and/or implement IT-based solutions;

9. Communicate effectively and efficiently with clients, user and peers, both orally and in writing;

10. Demonstrate independent critical thinking and problem solving skills;

11. Demonstrate an understanding of the impact of technology on individuals, organizations and society, including ethical, legal and policy issues;

12. Demonstrate an understanding of the need for continued learning throughout their career.

For each course in the IT program, there is an explicit statement of the program outcomes that it makes a contribution to. We return to this point below.

The Introduction to IT course (IT 1130) offered in the Department of IT at Georgia Southern University is the first course that students take in their major. It has two overall aims, namely (i) to introduce students to IT as a discipline and the overall structure of the IT degree program, and (ii) to cover some productivity tools, in particular Excel and Access. In line with all other IT courses at Georgia Southern University, IT 1130 was formulated through a set of explicit learning outcomes. The learning outcomes for IT 1130 are

1. Demonstrate a basic understanding of the field of IT, including the ability to 
i. Define the term "information technology";

ii. Recognize the disciplines that have contributed to the emergence of IT, namely computer science, information systems, and computer engineering;

iii. Identify areas in which IT has significantly impacted individuals, organizations and/or societies.

2. Demonstrate an understanding of basic information technology software applications, including the ability to

i. Using a given specification, create a simple database;

ii. Use SQL for simple queries;

iii. Use an office productivity suite.

It will be clear from the course outcomes that IT 1130 was designed to make a contribution to Program Outcomes 1, 2, 3, 10, and 11.

The overlap between Objective 1 in IT 1130 and the ITF knowledge area is significant; however, due to Objective 2, the introductory IT course at Georgia Southern must cover significant additional material over and beyond that specified in the IT fundamentals knowledge area. The next section discusses the relationship between IT 1130 and ITF knowledge area in more detail.

\section{Course Outline and Its Mapping to the IT Fundamentals Knowledge Area}

The Introduction to IT course at Georgia Southern consists of 45 lecture hours. Teaching productivity tools, learning outcome 2 for IT 1130, accounts for roughly nine hours of instruction. Exams conducted during the semester account for three hours of instruction. This leaves 33 lecture hours to cover the remaining topics for IT 1130 relating to Learning Outcome 1. Tables 1 and 2 assess the extent to which the IT 1130 course offered in the IT program at Georgia Southern University covers the ITF knowledge unit's learning outcomes. Table 1 provides (1) a breakdown of the topics covered in the remaining hours of instruction, (2) the number of lecture hours spent on that topic, (3) the learning outcome in the ITF knowledge area of the model curriculum to which the topic corresponds, and (4) the learning outcome for the course to which it corresponds. Therefore, Table 1 provides a mapping of IT 1130 course outcomes to the ITF knowledge area learning outcomes. Table 2 compares the number of hours of instruction in the IT 1130 course for each of the knowledge units in the IT fundamentals area to the minimum recommended number of lecture hours listed in the model curriculum. Table 2 also highlights the discrepancies between the ITF knowledge area in the model curriculum and the introductory IT course at Georgia Southern.

Table 1: IT 1130 Topics and ITF Learning Outcomes

\begin{tabular}{|l|c|c|c|}
\hline \hline IT 1130 Topic & $\begin{array}{c}\text { ITF Learning } \\
\text { Outcomes }\end{array}$ & \# Hours & $\begin{array}{c}\text { IT 1130 } \\
\text { Learning } \\
\text { Outcomes }\end{array}$ \\
\hline \hline 1 Define IT & ITF4.1 & 1 & $1 . \mathrm{i}$ \\
\hline 2 Data and Information & $\begin{array}{l}\text { ITF } 1.8 \\
\text { ITF1.9 }\end{array}$ & 1 & $1 . \mathrm{i}$ \\
\hline 3 Components of IT Systems & ITF1.1 & 8.5 & $1 . \mathrm{i}$ \\
\hline
\end{tabular}




\begin{tabular}{|c|c|c|c|}
\hline IT 1130 Topic & $\begin{array}{l}\text { ITF Learning } \\
\text { Outcomes }\end{array}$ & \# Hours & $\begin{array}{c}\text { IT } 1130 \\
\text { Learning } \\
\text { Outcomes }\end{array}$ \\
\hline $\begin{array}{ll}\text { - } & \text { Hardware } \\
\text { - Software } \\
\text { - Networks } \\
\text { - User } \\
\end{array}$ & & & \\
\hline $\begin{array}{l}\text { 4 Core Technologies } \\
\text { - Data Management } \\
\text { - Networking } \\
\text { - Web Systems } \\
\text { - SAD } \\
\text { - Programming } \\
\text { - HCI } \\
\text { - Specializations in BSIT }\end{array}$ & $\begin{array}{c}\text { ITF1.10 } \\
\text { ITF2.1 } \\
\text { ITF2.2 } \\
\text { ITF2.3 } \\
\text { ITF2.4 } \\
\text { ITF2.5 }\end{array}$ & 8.5 & $1 . \mathrm{i}$ \\
\hline 5 Related Disciplines & $\begin{array}{l}\text { ITF4.2 } \\
\text { ITF4.3 } \\
\text { ITF4.4 }\end{array}$ & 2 & 1.ii \\
\hline $\begin{array}{l}6 \text { Application Domains } \\
\text { (Second Disciplines in BSIT) }\end{array}$ & $\begin{array}{l}\text { ITF5.1 } \\
\text { ITF5.2 } \\
\text { ITF5.3 } \\
\text { ITF } 5.4 \\
\text { ITF } 3.2\end{array}$ & 7 & 1.iii \\
\hline 7 History of IT & $\begin{array}{l}\text { ITF3.1 } \\
\text { ITF3.4 }\end{array}$ & 1 & 1.iii \\
\hline $\begin{array}{l}8 \text { Viruses, Crime, Law, Ethics, Privacy \& } \\
\text { Security }\end{array}$ & $\begin{array}{l}\text { ITF } 1.11 \\
\text { ITF } 3.2\end{array}$ & 3 & 1.iii \\
\hline 9 IT as a Profession & $\begin{array}{l}\text { ITF1.5 } \\
\text { ITF1.6 } \\
\text { ITF1.7 } \\
\text { ITF1.10 }\end{array}$ & 1 & 1 \\
\hline TOTAL & & 33 & \\
\hline
\end{tabular}

Table 2: Comparison of IT 1130 to ITF Knowledge Area

\begin{tabular}{|c|c|c|c|}
\hline $\begin{array}{c}\text { ITF Knowledge } \\
\text { Units }\end{array}$ & ITF Recommended & IT 1130 & $\begin{array}{c}\text { ITF Learning Outcomes } \\
\text { Not Covered }\end{array}$ \\
\hline ITF1 & 17 & 14 & $1.2,1.3,1.4$ \\
\hline ITF2 & 6 & 7.5 & 3.3 \\
\hline ITF3 & 3 & 2 & \\
\hline ITF4 & 3 & 3 & \\
\hline
\end{tabular}




\begin{tabular}{|c|c|c|c|}
\hline ITF5 & 2 & 6.5 & \\
\hline ITF6 & 2 & Not Covered & $6.1-6.7$ \\
\hline \hline TOTAL & 33 & 33 & \\
\hline \hline
\end{tabular}

The ITF knowledge area has several learning outcomes that are not covered in IT 1130, namely Outcomes 1.2, 1.3, 1.4, 3.3 and 6.1 - 6.7. The next section discusses these discrepancies.

\section{Some Observations}

Table 2 illustrates several noteworthy differences between the IT 1130 course at Georgia Southern University and the knowledge units in the ITF knowledge area.

A discrepancy exists between the minimum number of hours recommended for ITF1 (pervasive themes in IT) and the number of hours taught in IT 1130. The three hour discrepancy can be attributed to the lack of coverage in IT 1130 of outcomes ITF 1.2 - 4. Thus, IT 1130 provides no explicit coverage of the reasons for the emergence of complexity in IT, the need for IT professionals to handle complexity, and the tools and techniques available to an IT professional in IT1130. Instead, the IT program at Georgia Southern covers complexity-related issues in a number of courses throughout the curriculum. For example, some complexity-related issues are discussed in a two-course sequence of Java programming courses. Standards are discussed in a number of courses throughout the curriculum, including a data communication course, a web design course in which students learns how to implement n-tier architectures, and a course on software acquisition, implementation, and integration. Finally, complexity related issues are also covered in a capstone course on IT issues and management. Since the need to manage complexity is identified in the IT model curriculum as a pervasive theme, this is a reasonable alternative to cover this issue.

The IT 1130 course devotes more lecture hours than the minimum recommendation to ITF2 (organizational issues) and ITF5 (application domains). As the recommendation is a minimum, this is not problematic; however, it is worth noting that the explanation for these discrepancies relates directly to the structure of the IT major at Georgia Southern University.

The additional lecture hours relating to ITF2 (organizational issues) are due to the coverage of the structure of the IT degree in the IT 1130 course. IT majors are expected to take a number of core courses, including courses in programming; web design; software acquisition, implementation, and integration; networking; systems analysis and design; data management; and project management. In addition, IT majors specialize in knowledge management and IT integration, systems development and support, telecommunications and network administration, or web and multimedia foundations. It is useful to students beginning their academic programs in IT to receive information on the structure of the core of the program, its constituent courses and how they relate, and on the different specializations available to them. Since, for most IT majors, IT 1130 is the first course in the program, it is the logical place to meet this aim. Clearly, a full discussion of the structure of the program covers more than just data management (ITF1.10), a broad overview of IT applications (ITF2.1) and their development (ITF2.2), systems analysis (ITF2.3), project management (ITF2.4), and IT integration (ITF2.5). This explains why IT 1130 devotes one and onehalf more hours than the recommended minimum six.

The additional lecture hours in ITF5 (application domains) are due to the coverage of the second disciplines available to IT majors in the IT 1130 course. One of the explicit program outcomes of the BS in IT program at Georgia Southern is that, on graduation, graduates will be able "to dem- 
onstrate sufficient understanding of an application domain to be able to develop IT applications suitable for that application domain." This outcome was included at the recommendation of industry representatives who were consulted when the IT program was designed (Reichgelt et al., 2002a). For students to develop this ability, they must be exposed to an IT application domain, and, as a result, the BS IT program at Georgia Southern contains second disciplines. As stated in the introduction, students typically start taking courses in their second discipline early in their program of study (the standard program of study suggests that students take their first second discipline course in the first semester of their sophomore year). It is, therefore, important that students be exposed to the different second disciplines available to them early, and IT 1130 is the logical place to do so. One fortunate side effect of the need to introduce a second discipline is that it gives the program an excellent opportunity to make students aware of the broad range of areas in which IT can be applied and, hence, cover ITF5 (application domains); however, since the number of second disciplines is large (26 as of January 2006), adequate coverage requires four and one-half hours more than the minimum recommend coverage for ITF 5 (application domains).

One lecture hour is missing in ITF3 (history of IT) due to lack of coverage in the IT 1130 course of significant changes in HCI (ITF3.3). Some material relevant to this topic is introduced in other courses that students tend to take early in their programs of study, such as the introductory Java course and the introductory web design course. For example, the introductory web design course includes among its course objectives that students develop the ability to design Web pages in accordance with good design principles using appropriate styles and formats and the ability to design Web pages that are ADA compliant. Material relevant to both objectives allows HCI design principles to be expanded and placed in a historical context. Moreover, students are advised to take the introductory web design course in the semester following the one in which they take IT 1130 , and they are, therefore, likely to be exposed to material relevant to ITF3.3 early in their programs of study.

The final discrepancy lies in the coverage of the learning outcomes corresponding to the ITF6 (application of math and statistics to IT) in the IT 1130 course; however, the material related to this knowledge unit is covered in two courses that students are again advised to take early in their programs of study. One course is in discrete mathematics, designed specifically for IT majors. It includes among its course objectives the ability to explain the importance of discrete mathematics in computer science and information technology and provides in-depth coverage of functions, sets, basic propositional logic, and algorithm design. Finally, all students enrolled in the IT major take a statistics course, which covers probability.

\section{Support Material}

Since the ITF knowledge area is relatively new, no single textbook covers all relevant material. Georgia Southern, therefore, uses a variety of sources to support the course. The sources are:

- Excel 2003 (Shelley, Cashman, \& Quasney, 2004) and Access 2003 (Shelley, Cashman, Pratt, \& Last, 2004) to support the teaching of spreadsheets and SQL (IT 1130 course outcomes 2i-2iii identified in the section "The Introduction to IT Course at Georgia Southern University").

- To support the teaching of Topics 3 (components of IT systems), 4 (core technologies), and 7 (history of IT) in the IT 1130 course (topics are listed in Table 1), Georgia Southern uses Discovering Computers 2005 (Shelley, Vermaat, \& Cashman, 2005). While the textbook provides a reasonable coverage of some of the subtopics discussed, it does not 
sufficiently stress the importance of users and HCI in systems development, and throughout the course.

- For Topics 6 (application domains), 8 (viruses, crime, law, ethics, privacy, and security), and 9 (IT as a profession), Georgia Southern uses Computers in Our World (Jedlicka, 2003); however, Georgia Southern does not rely solely on the textbook for coverage of Topic 6, as custom support material has been designed to introduce students to second disciplines.

- To support Topics 1 (define IT), 2 (data and information), and 5 (IT and its related disciplines), students are given material written specifically for the course. Also, representatives from computer science and information systems are invited to lecture on their specific disciplines. These guest speakers are followed by lectures on computer engineering and a discussion on the relationship between all four disciplines.

Table 3 lists the core learning outcomes for each of the ITF knowledge units and maps them to the material in the IT 1130 course used to achieve that outcome. The material comes either from Discovering Computers 2005 (Shelley et al., 2005) (DC), Computers in Our World (Jedlicka, 2003) (CIOW), or material written specifically for the course (supplemental material) and/or lectures/discussions led by faculty members from other related departments.

Table 3: Course Materials Used in IT 1130 to Achieve ITF Learning Outcomes

\begin{tabular}{|c|c|l|}
\hline $\begin{array}{c}\text { ITF Knowl- } \\
\text { edge Units }\end{array}$ & $\begin{array}{c}\text { Learning } \\
\text { Outcomes }\end{array}$ & \multicolumn{1}{|c|}{ Material } \\
\hline \multirow{4}{*}{ ITF 1 } & 1 & DC Chapters 3-9 \\
\cline { 2 - 3 } & $2-4$ & Not covered \\
\cline { 2 - 3 } & $5-7$ & $\begin{array}{l}\text { DC Chapters 12 \& 15, CIOW Chapters 8 \& 9, Supplemental } \\
\text { Materials }\end{array}$ \\
\cline { 2 - 3 } & $8-9$ & DC Chapter 10, Supplemental Materials \\
\cline { 2 - 3 } & 10 & DC Chapters 2, 9, 10,12, 13, Supplemental Materials \\
\hline ITF2 & 11 & CIOW Chapters 7-9 \\
\hline ITF3 & 1 & DC Chapters 2, 9, 10, 12, 13. Supplemental Materials \\
\cline { 2 - 3 } & 2 & CIOW Chapters 1 - 9 \\
\cline { 2 - 4 } & 3 & Not covered \\
\hline ITF 4 & $1-4$ & $\begin{array}{l}\text { Supplemental Materials, Lecture and Class Discussion led by } \\
\text { CS, IS and IT representatives }\end{array}$ \\
\hline ITF5 & $1-4$ & CIOW Chapters 1 - 9 \\
\hline ITF6 & $1-7$ & Not covered \\
\hline
\end{tabular}




\section{Assessment}

In addition to making sure that the learning outcomes for a particular knowledge area in the IT model curriculum are covered in a degree program, an academic unit must also assess the extent to which students achieve the learning outcomes set forth in the course. As many IT programs differ in how they offer degree programs, academic units must also assess whether the learning outcomes in the courses they offer match the outcomes set forth in the model curriculum. Some schools have developed a separate information system solely for assessing their courses (Drinka, Voge, \& Yen, 2005). Information gained through the assessment process is used for continuous improvement (Drinka et al., 2005). Indeed, many accreditation agencies, such as ABET (www.abet.org) and AACSB (www.aascb.edu) and the various regional accreditation agencies, insist that programs or institutions have an appropriate assessment and continuous improvement strategy in place before they are accredited.

The previous sections demonstrated that the IT program at Georgia Southern University covers the learning outcomes listed in the ITF knowledge area prescribed by the IT model curriculum. Moreover, the bulk of these learning outcomes are covered in the IT 1130 course. In order to determine the extent to which students achieve the learning outcomes set forth in the IT 1130 course, which are in alignment with most of the ITF knowledge area learning outcomes (see Table 1), instructors teaching the course have developed an assessment strategy that maps each of the various student assessment instruments (e.g., exams, projects) used in the course to a course learning outcome. Table 4 lists the pieces of assessment in IT 1130 and the total number of points each piece is worth.

Table 4: Assessment in IT 1130

\begin{tabular}{|l|c|}
\hline Assessment & Total points \\
\hline Assignment 1 - Excel & 80 \\
Assignment 2 - Excel & 80 \\
Assignment 3 - Access & 80 \\
Assignment 4 - Access & 80 \\
Assignment 5 - Difference between IT, IS, CS, CE & 80 \\
Assignment 6 - Second Disciplines & 100 \\
Midterm & 200 \\
Final Exam - Part 1: Multiple Choice, Part II: SQL Queries & 300 \\
\hline Total & $\mathbf{1 0 0 0}$ \\
\hline
\end{tabular}

In order to measure the extent to which each student achieves the outcomes set forth in IT 1130, the pieces of assessment are aligned with the learning outcomes from IT 1130. Table 5 provides a mapping of the learning outcomes in IT 1130 to the pieces of assessment used in the course as well as the percentage of students that achieved that objective in Summer 2005 by receiving a minimum of 70 percent for that assessment. Table 5 also provides a mapping of the learning outcomes in the ITF knowledge area to the pieces of assessment used in IT 1130. To assess Learning Outcome 1, multiple choice questions on the midterm and final exam were used as well as two writing assignments (Assignment $5 \& 6$ ). Note that the final exam is divided into two parts. The first part is multiple choice questions. Part of the multiple choice questions assess Learning Outcome 1i. while the rest assesses Outcome 1iii. The grade for each set of multiple choice questions was recorded separately in order to determine the percentage of students who achieved each of these learning outcomes with a passing score (above 70 percent). The second part of the final exam asked students to write some SQL queries. This part of the exam was used to assess Learning Outcome 2ii. Note that the majority of students achieved Learning Outcome 1 with the lowest 
percentage of students passing a particular piece of assessment being 80 percent. To assess Learning Outcome 2, a variety of Excel and Access assignments were used as well as the SQL part of the final exam. The majority of students achieved Learning Outcome 2 with the lowest percentage of student passing a particular piece of assessment being 70 percent.

Table 5: Success rate of students for each learning outcome

\begin{tabular}{|c|c|c|c|}
\hline IT 1130 Learning Outcome & $\begin{array}{l}\text { ITF Learning } \\
\text { Outcome }\end{array}$ & Assessment & $\begin{array}{c}\% \\
\text { Achieved }\end{array}$ \\
\hline $\begin{array}{l}\text { 1. Demonstrate a basic understanding } \\
\text { of the field of IT, including the abil- } \\
\text { ity to: }\end{array}$ & $1.5,1.6,1.7,1.10$ & Midterm Exam & 95 \\
\hline $\begin{array}{l}\text { 1i. Define the term "information } \\
\text { technology"; }\end{array}$ & $\begin{array}{l}1.1,1.8-1.10,2.1 \\
-2.5,4.1\end{array}$ & $\begin{array}{l}\text { Midterm Exam } \\
\text { Final Exam - } \\
\text { Multiple Choice }\end{array}$ & $\begin{array}{c}95 \\
100\end{array}$ \\
\hline $\begin{array}{l}\text { 1ii. Recognize the disciplines that } \\
\text { have contributed to the emergence of } \\
\text { IT, namely computer science, infor- } \\
\text { mation systems, and computer engi- } \\
\text { neering; }\end{array}$ & $4.2-4.4$ & Assignment 5 & 100 \\
\hline $\begin{array}{l}\text { 1iii. Identify areas in which IT has } \\
\text { significantly impacted individuals, } \\
\text { organizations and/or societies. }\end{array}$ & $1.11,3.1,3.2,3.4$ & $\begin{array}{l}\text { Assignment } 6 \\
\text { Final Exam - Multi- } \\
\text { ple Choice }\end{array}$ & $\begin{array}{l}100 \\
80\end{array}$ \\
\hline $\begin{array}{l}\text { 2. Demonstrate an understanding of } \\
\text { basic information technology soft- } \\
\text { ware applications including the abil- } \\
\text { ity to: }\end{array}$ & & Assignment $1 \& 2$ & 90 \\
\hline $\begin{array}{l}\text { 2i. Using a given specification, create } \\
\text { a simple database; }\end{array}$ & & Assignment 3 & 70 \\
\hline 2ii. Use SQL for simple queries & & $\begin{array}{l}\text { Assignment } 4 \\
\text { Final Exam - SQL } \\
\text { Queries }\end{array}$ & $\begin{array}{l}95 \\
90\end{array}$ \\
\hline 2iii. Use an office productivity suite & & $\begin{array}{l}\text { Assignment } 1 \\
\text { Assignment } 2 \\
\text { Assignment } 3 \\
\text { Assignment } 4\end{array}$ & $\begin{array}{l}90 \\
80 \\
70 \\
95\end{array}$ \\
\hline
\end{tabular}

\section{Conclusion}

The IT Fundamentals knowledge area in the IT model curriculum is of central importance to the design of an introductory IT course; however, since institutions will have to include additional materials in their introductory IT courses, depending on the nature of their programs, the mini- 
Implementation of the IT Fundamentals Knowledge Area

mum requirement of 33 lecture hours to cover this material is likely to lead to problems. This paper presents the experience with an introductory IT course at Georgia Southern University, IT 1130. In general, the authors believe that, despite the need to include additional material in IT 1130 , they are able to cover most of the knowledge units in the IT fundamentals knowledge area. They are confident that those knowledge units not covered in IT 1130 are covered in other courses that students are advised to take early in their programs of study.

Despite the fact that the IT fundamentals knowledge area is new and that no textbooks cover all the knowledge units within the area, faculty members have been able to identify a set of textbooks that, jointly, cover most of the material; however, they provide a relatively small amount of additional material, and the textbooks they identified do not always cover the material at the appropriate level. Therefore, support materials specifically for the IT fundamentals knowledge area need to be developed. Whether this is best provided in the form of a textbook, or, more dynamically, as a set of online learning objects (Abernethy, Treu, Piegan, \& Riechgelt, 2005a, 2005b) is a question open to debate.

Finally, the paper discusses the assessment strategy used for the IT 1130 course at Georgia Southern University. The authors provide evidence that the students are achieving the learning outcomes set forth in the course and, therefore, are achieving the related outcomes in the ITF knowledge area in the IT model curriculum. This is based on the results of one course to date, but collection of data to assess the success of students in achieving the learning outcomes in IT 1130 is an ongoing process at Georgia Southern to continually improve its program.

\section{References}

Aasheim, C., Lee, C.-K., \& Reichgelt, H. (2005). Implementing the IT fundamentals knowledge area. Proceedings of SIGITE 05, Newark, NJ., 1-5.

Abernethy, K., Treu, K, Piegari, G., \& Reichgelt. H. (2005a). An implementation model for a learning object repository. E-learn 2005 World Conference on E-learning in Corporate, Government, Healthcare and Higher Education, Vancouver, Canada.

Abernethy, K., Treu, K., Piegari, G., \& Reichgelt. H. (2005b). A learning object repository in support of introduction to information technology. $6^{\text {th }}$ Annual Conference for the Higher Education Academy Subject Network for Information and Computer Science, York, England.

Drinka, D., Voge, K., \& Yen, M. (2005). From principles to practice: Analyzing a student learning outcomes assessment system. Journal of Cases on Information Technology, 7(3), 37-56.

Jedlicka, L. (2003). Computers in our world. Boston, MA: Thompson Course Technologies.

Lawson, E., Reichgelt, H., Lunt, B., Ekstrom, J., Kamali, R., Miller, J., \& Gorka, S. (2005). The information technology model curriculum. Columbus, OH: ISECON.

Reichgelt, H., Price, B., \& Zhang, A. (2002a). Designing an information technology curriculum: The Georgia Southern experience. Journal of Information Technology Education, 1(4), 213-221.

Reichgelt, H., Price, B., \& Zhang, A. (2002b). The inclusion of application areas in IT curricula. SIGITE3 , Rochester, NY, ACM-SIGITE (formerly SITE).

Shelley, G., Cashman, T., Pratt, P., \& Last, M. (2004). Microsoft Office Access 2003. Boston, MA: Thompson Course Technologies.

Shelley, G., Cashman, T., \& Quasney, J. (2004). Microsoft Office Excel 2003. Boston, MA: Thompson Course Technologies.

Shelley, G., Vermaat, M., \& Cashman, T. (2005). Discovering computers 2005: A gateway to information. Boston, MA: Thompson Course Technologies. 


\section{Biography}

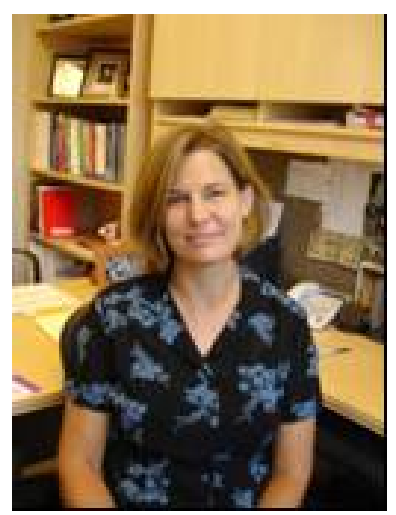

Dr. Cheryl Aasheim received her B.S. in Mathematics, M.S.T. in Mathematics and Ph.D. in Decision and Information Sciences (2002) from the University of Florida. Dr. Aasheim has taught at the University of Florida and Santa Fe Community College as an adjunct instructor. While teaching as a graduate student at the University of Florida, she won the University-wide award for "Outstanding Service as a Graduate Teaching Assistant." Her research interests include information retrieval, text classification, data mining, decision support systems and IT education. Dr. Aasheim's publications include refereed journal articles, book chapters and proceedings in national and regional conferences.

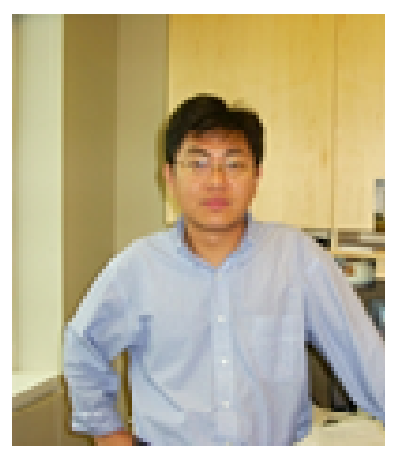

Dr. Choong Kwon Lee has been serving as an assistant professor at Georgia Southern University since August 2003. Prior to that, Dr. Lee worked from 1995-1997 as systems analyst at Korea Aerospace Research Institute. Dr. Lee received his Ph.D. from University of Nebraska-Lincoln. Dr. Lee continues his active research in the fields of "IT Job Skills for the New Millennium" and "Strategic Uses of IT."

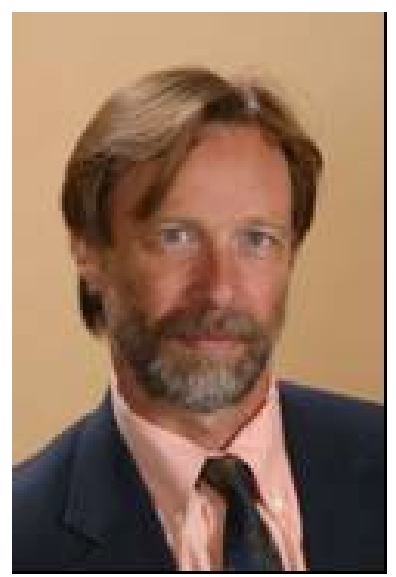

Han Reichgelt holds degrees in Philosophy and Psychology from the University of Nijmegen in the Netherlands, and a PhD in Cognitive Science from the University of Edinburgh in Scotland. Previously, he was a research fellow at the University of Edinburgh, lecturer in Psychology at the University of Nottingham, and professor of Computer Science at the University of the West Indies, Mona, Jamaica. His current position is Associate Dean of the College of Information Technology at Georgia Southern University. Han is the (co-) author of over seventy journals and refereed conference papers and a textbook on Knowledge Representation in Artificial Intelligence. His research interests include IT and economic development, IT application delivery quality, business process modeling and computing education. He currently chairs the ACM Special Interest Group on IT Education. 